بثزوهشهاى زنتيك گياهى / جلد ع / شماره Y /

تجزيه ميانخين نسل ها براى مقاومت به بيمارى ساقه سياه در آفتابخردان (Helianthus annuus L.) با استفاده از مدلهاى خطى مخلوط

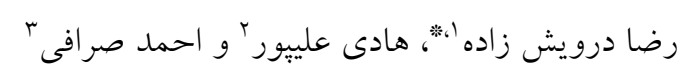

1- استاد، گروه اصلاح و بيوتكنولوزى گياهى، دانشكده كشاورزى، دانشخاه اروميه، اروميه

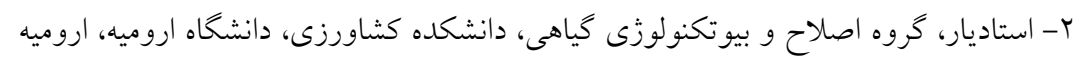

r- استاد، آزمايشگاه اكولوزى عملكردى، مدرسه عالى ملى زراعت تولوز، انستيتو ناسيونال يلى تكنيك، تولوز، فرانسه

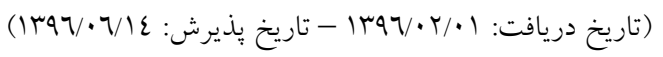

بيمارى ساقه سياه يكى از بيمارىهاى مهم قاريحى آفتابخردان است. اطلاع از نحوه توارث و كنترل زنتيكى صفت اهميت ويزه

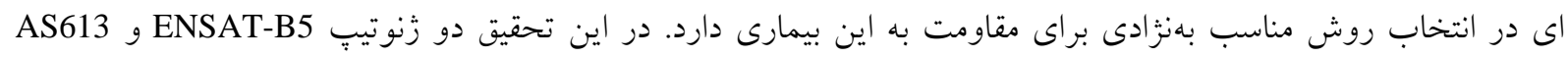

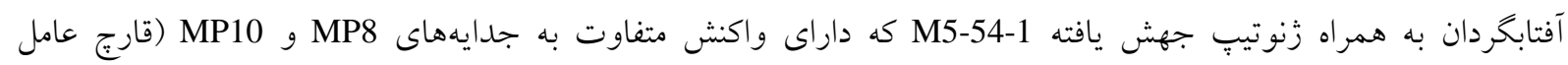

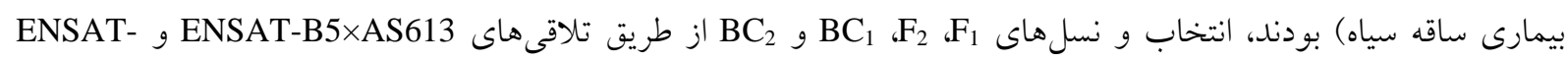

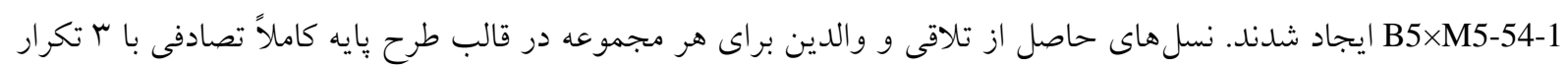

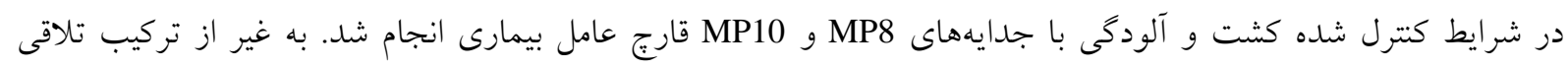

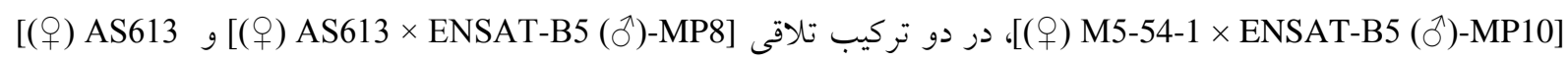
× ENSAT-B5 (ठึ)-MP10]

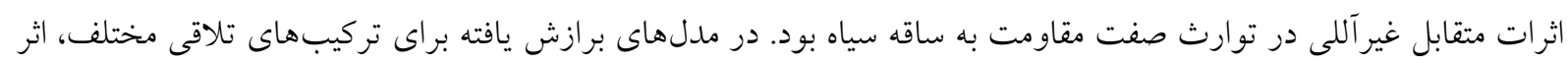

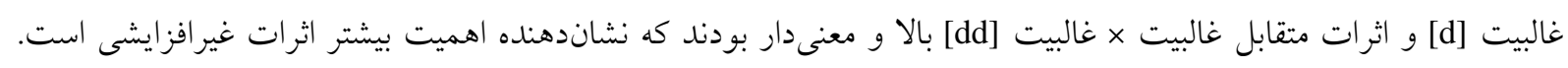

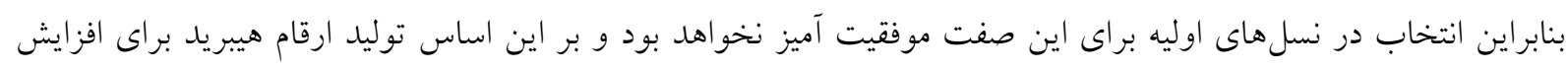
مقاومت به بيمارى ساقه سياه توصيه مى شوداب. وازگًان كليدى: اثرات غير افزايشى، إيستازى، تنش زيستى، گياهان دانه روغنى، طرح آميزشى 
Lamkey, 2003; Butruille et al., 2004; Mihaljevic et al., 2005; Checa et al., 2006; Zalapa et al., 2006; Kashiwagi et al., 2008; Kusterer et al., 2007; كه در اين (Malvar et al., 2008; Smith et al., 2009 روش علاوه بر اثرات افزايشى و غالبيت زنها، اثرات إيستازى زنها از قبيل افزايشى × افزايشى، غالبيت × غالبيت و افزايشى × غالبيت نيز قابل برآورد است

Mather and Jinks, 1971; Lynch and Walsh, 1998; )

Kearsey and Pooni, 1996; Dorri et al., 2015; Molaei et al., 2016 (et). بسيارى از شواهد حاكى از آن است كه هميشه نمىتوان اثر ابيستازى را ناجيز در نظر كرفت

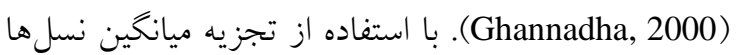
براى صفات مختلف زراعى در آفتابخردان نشان داده شد كه اثر ابيستازى نقش به سزايى در كنترل اين صفات دارند (Jovanovic and Marinkovic, 2006) اثر زنها در بسيارى از گياهان زراعى مطالعه شده است

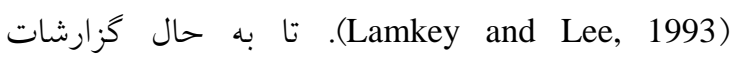
معدودى در رابطه با شناسايى اثرات زنى مرتبط با بيمارى ساقه سياه در آفتابخردان ارائه شده است ( Darvishzadeh .et al., 2008a

در تجزيه ميانخين نسلها عمدتا از آزمون مقياس ماتر يا آزمون مقياس مشترك كاوالى ب براى بررسى كفايت مدل افزايشى - غالبيت و برآورد اثرات زنتيكى استفاده مىشود. در اينجا آزمون نيكويى برازش بَ با آزمون t يا مربع كاى

Kearsey and Pooni, 1996; Mather ) انجام مى كيرد (and Jinks, 1971 در اين روشها خطاها براساس واريانس داخل كرتها برآورد مى گردند ( Mather and (Jinks, 1971 در اين حالت جون واريانس بين كرتها ناديده كرفته مىشود نتايج ممكن است زياد دقيق نباشد ز (Piepho and Mohring, 2010) محققين تجزيه واريانس استاندارد بر مبناى ميانخين كرت انجام مىدهند كه يك خطاى ثابت ساده را براى آزمون اثرات در نظر مى گيرد. در اين تجزيهها خطاى بين كرتها

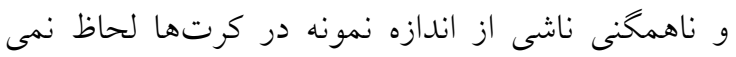

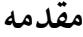

آفتابخردان (Helianthus annuus L.) كياهى از خانواده كل ستارهاىها (Asteraceae) به عنوان يكى از منابع مهم توليد روغن خوراكى در دنيا به شمار مىرود ( Hu et al., 2010). ويزگ كاى منحصر به فرد اين گياه از جمله

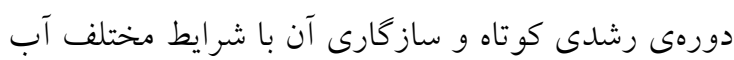
و هوايى، آفتابخردان را به كياهى مناسب جهت كشت در نواحى خشك با ميزان بارندكى كم تبديل كرده است

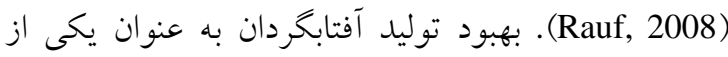
مهمترين گياهان دانه روغنى در دنيا مىتواند نقطهى اميدى براى جبران كاستى روغن گياهى مورد نياز كشور باشد. علاوه بر تنشهاى غير زيستى، تنشهاى زيستى بويزه بيمارىهاى گياهى ناشى از قارج ها از عوامل بسيار مهم كاهش توليد محصولات كثاورزى در سراسر جهان مىباشند. بيمارى ساقه سياه يكى از بيمارىهاى مهم آفتابخردان است كه بوسيله قارج Phoma macdonaldii ايجاد مىشود (Sackston, 1992). اين بيمارى باعث ايجاد لكههاى سياه روى دمبرى و ساقه شده و موجب كاهش •ا تا •ب درصدى عملكرد دانه و كاهش درصد روغن مىشود (Carson, 1991). كاهش عملكرد دانه آفتابخردان بويزه زمانى كه بيمارگر موجب بيرى زودرس گياه شود، بسيار بالا است (Debaeke and Peres, 2003). همجِنين آلودگى با قارج عامل بيمارى در رطوبت بالا و بعد از كلدهى بسيار شديد است (Gulya et al., 1997). استفاده از ارقام مقاوم به بيمارى، يكى از اقتصادىترين روشهاى

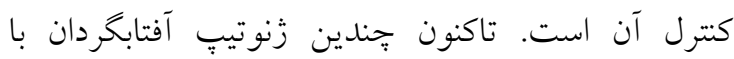
سطوح مختلف مقاومت به اين بيمارى گزارش شده است، ولى هنوز زنوتيىى با مقاومت كامل به بيمارى ساقه سياه شناسايى نشده است (Roustaee et al., 2000a). اطلاع از نحوه توارث و كنترل زنتيكى صفات اهميت ويزه Lamkey and ) اى در انتخاب روش مناسب بهنزادى دارد (Lee, 1993 يكى از بهترين روشها براى تعيين بارامترهاى زنتيكى، روش تجزيه ميانخين نسلها است Wilson et al., 2000; Butron et al., 2002; Hinze and ) 
هر دو جدايه بودند. زنوتيّ M5-54-1 مقاوم به جدايه

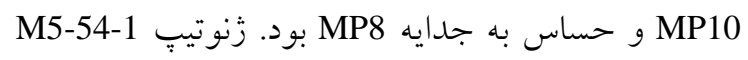

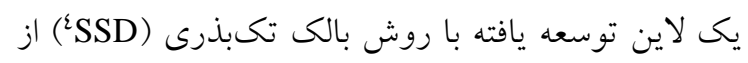

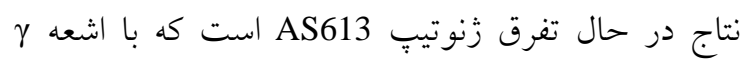

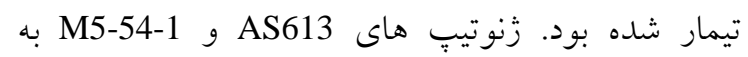

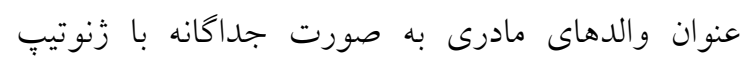

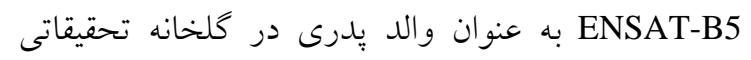
آزمايشگاه اصلاح و بيوتكنولوزى كياهى INP-ENSAT در مبرا تلاقى داده شد. بررسى صحت تلاقى هاى انجام يافته با تعدادى نشانكر ميكروساتليت (SSR كرفت. نسل هاى در حال تفرق تلاقى ها FC در سال (شامل والدين و نسل هاى BC و BC

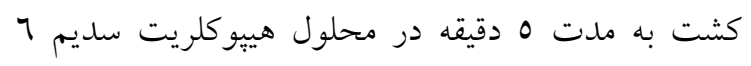

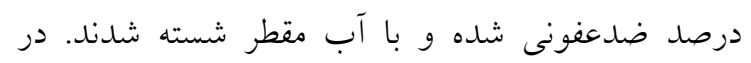

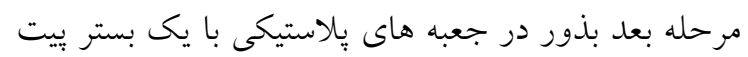

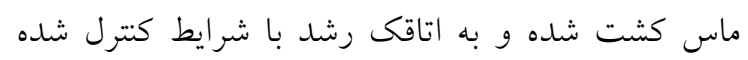

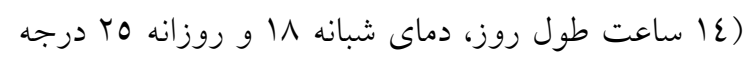

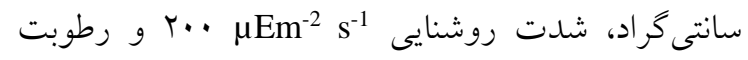

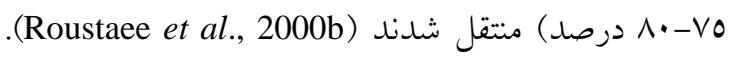
بررسى نسلهاى هر مجموعه در قالب طرح پِايه كاملاً

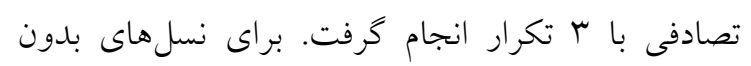

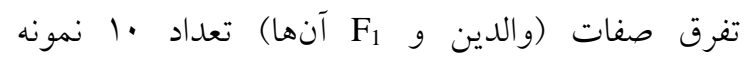

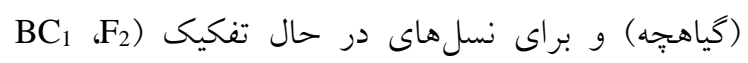

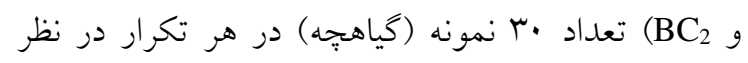
كرفته شد. بعد از •ا روز انكوباسيون جدايههاى قارج در شرايط

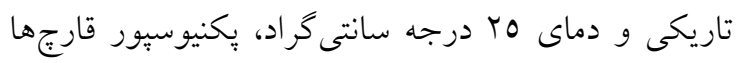

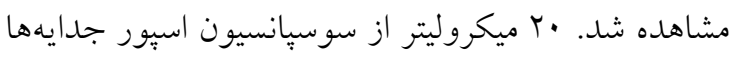

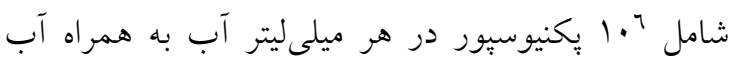

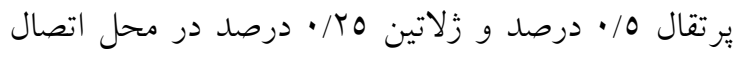

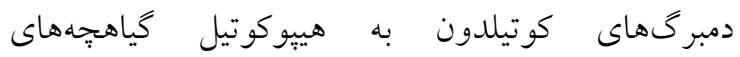
أفتابخردانهاى ع بركى ريخته شد ( Roustaee et al.

4- Single-seed descent

5- Simple sequence repeat
شود و همجنين از اين واقعيت كه بخشى از واريانس درون كرت در نسل هاى در حال تفرق (BC (Fiepho, 1997) منشأ زنتيكى دارد، غفلت مى (F)

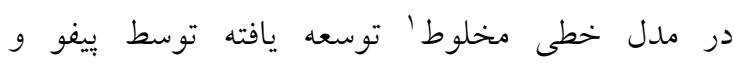

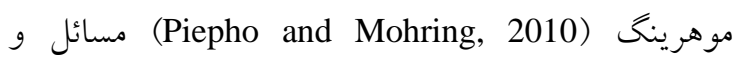
مشكلات روشهاى قبلى حل شده و و برآورد اثرات زنتيكى و تجزيه ميانكين و واريانس نسل ها در يكى مرحله

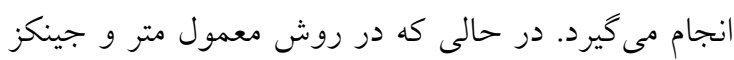
تجزيه ميانگين و واريانس (Mather and Jinks, 1971) نسلها به صورت جداكانه انجام مىشود كه هر كدام شامل جندين مرحله مى باشند.

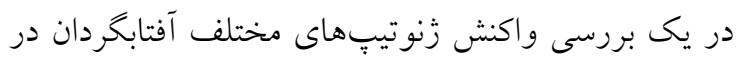

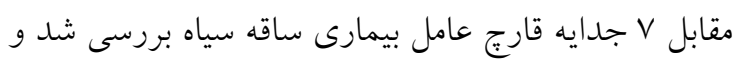

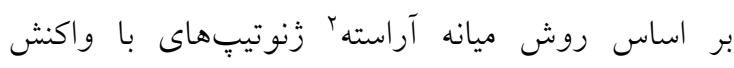

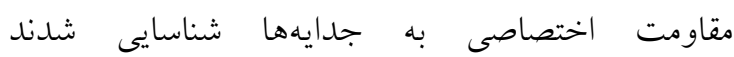
(Darvishzadeh et al., 2007)

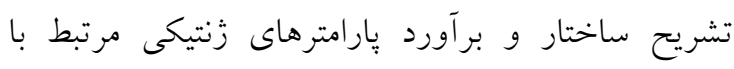

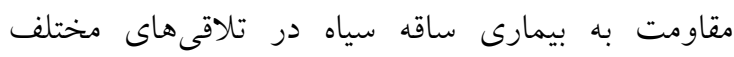

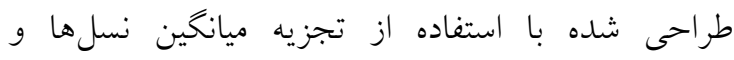
براساس مدل خطى مخلوط انجام شد تا بتوان بهترين

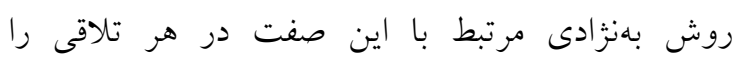
شناسايى و در برنامههاى بهنزادى استفاده نمود.

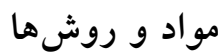

مواد گياهى مورد استفاده در اين تحقيق شامل دو زنوتيب ENSAT-B5 و AS613 به همراه زنوتيب جهش يافته M5-54-1 آفتابخردان بودند كه براساس مطالعات فنوتييى Darvishzadeh (Darvishzadeh et al., 2007) MP8 داراى واكنش متفاوت به جدايههاى (et al., 2008b

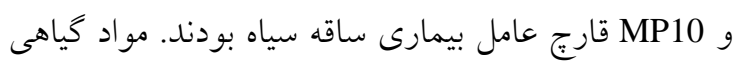

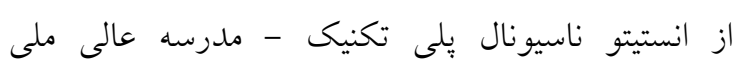

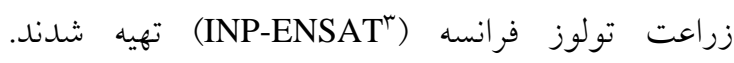

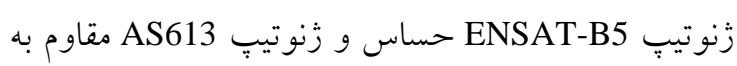

1- Mixed linear model

2- Median polish

3- Institut National Polytechnique-École Nationale Supérieure Agronomique de Toulouse 
باشد. همخنى واريانس نسل ها با اضافه كردن و نكردن

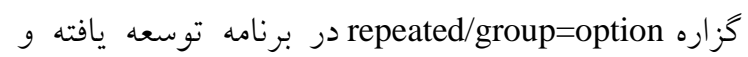

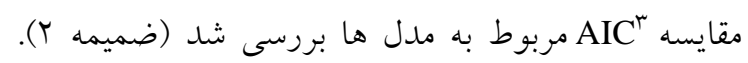

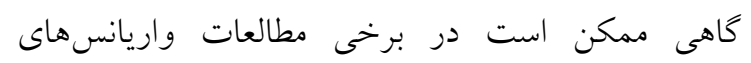

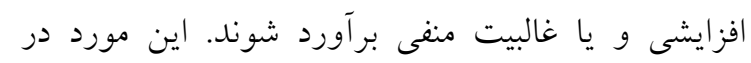

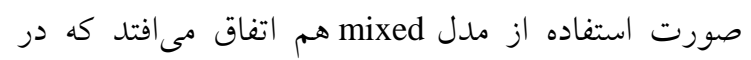

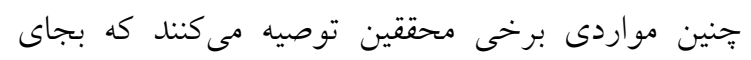

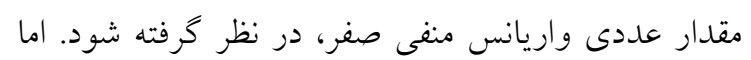
در مطالعه حاضر، براساس نظر Professor Hans-Peter Piepho كزاره lowerb=option استفاده شد و واريانسها تصحيح شدند (مكاتبات شخصى) (ضميمه س). نتايج و بحث مقايسه ميانخين صفت در نسلهاى مختلف براى تركيب

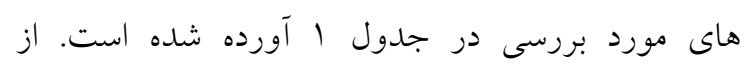

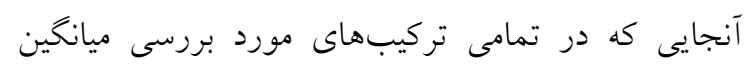

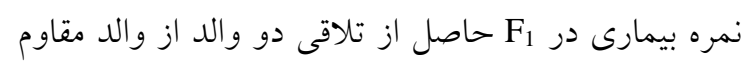

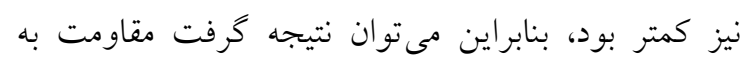

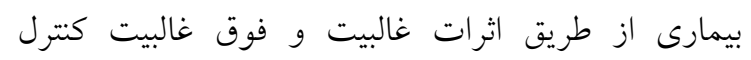

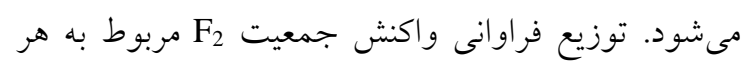

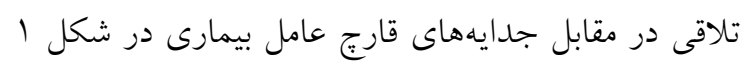

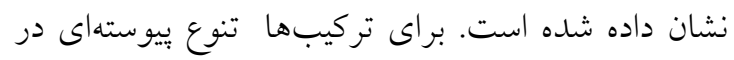

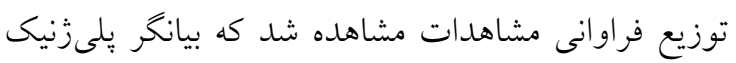

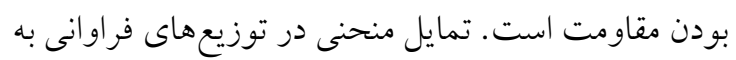
يك جهت خاص نشان مىدهد كه غالبيت به طرف آن

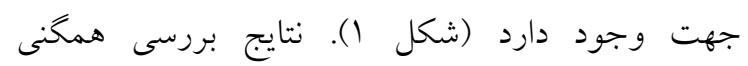
واريانس نسلها نشان داد كه مقدار عددى AIC وقتى دارد

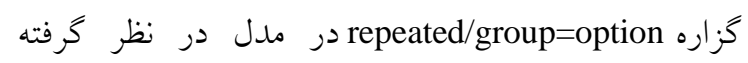
مىشود كمتر از حالتى است كه گزاره repeated از مدل

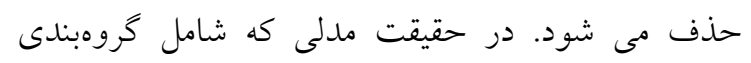

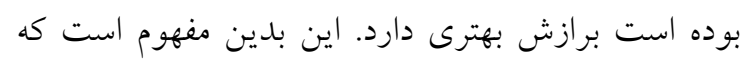

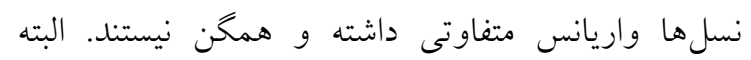

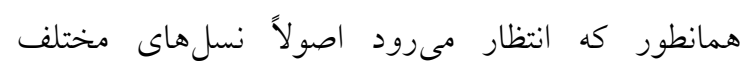

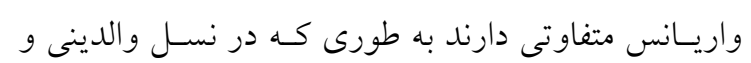

3- Akaike information criterion

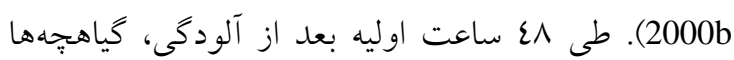

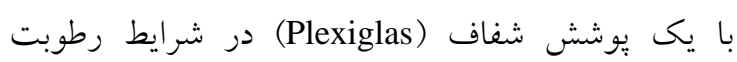

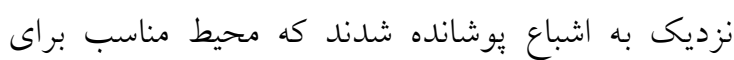

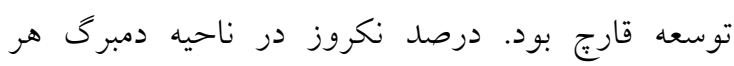

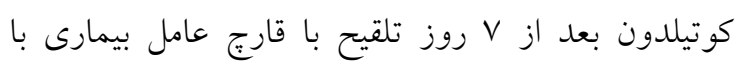

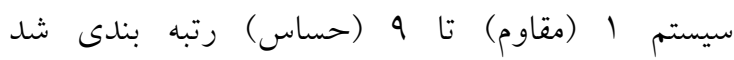
(Roustaee et al. 2000b)

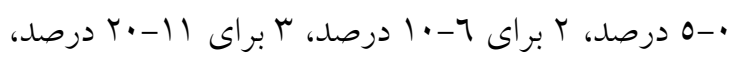

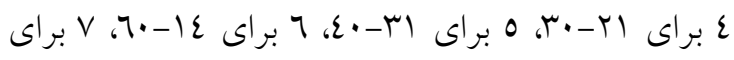

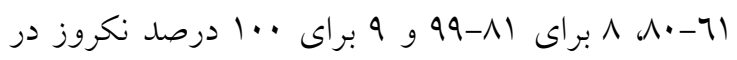

نظر كرفته شد (Roustaee et al. 2000b). تجزيه ميانحين نسل ها بر اساس مدل زير (Rather and (Jinks, 1971

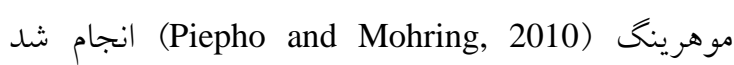
(ضميمه (1). $\mathrm{Y}=\mathrm{m}+\alpha \mathrm{a}+\beta \mathrm{d}+\alpha^{2} \mathrm{i}+2 \alpha \beta \mathrm{j}+\beta^{2}$ در اين فرمول Y ميانخين نسل، m ميانخين همه نسل ها در

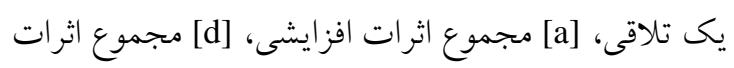

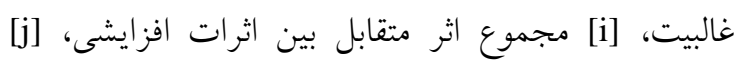

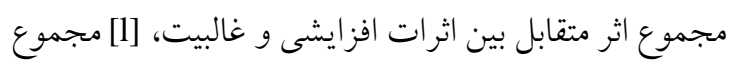

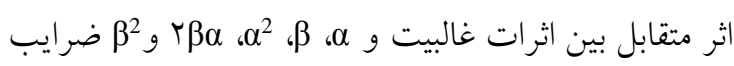
بارامترهاى زنتيكى مى باشند. در برنامه توسعه يافته، كفايت

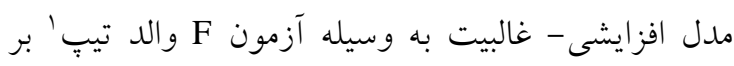

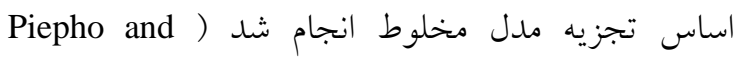

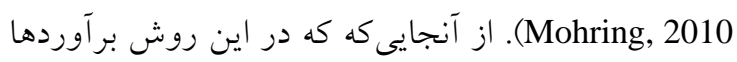

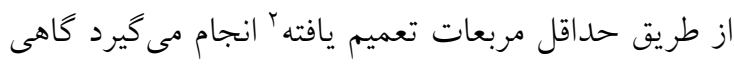

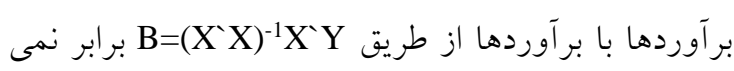
باشند. نرمال بودن توزيع دادهها كنترل نشد. در صورتى كه براى

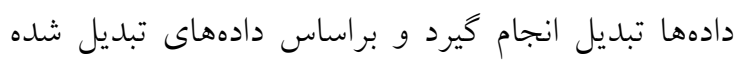

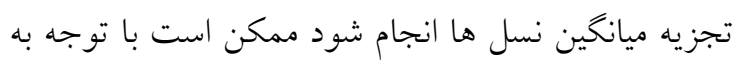

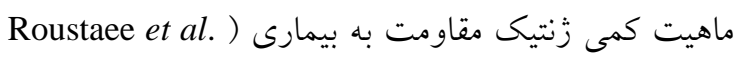

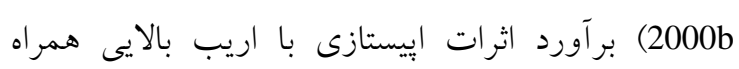



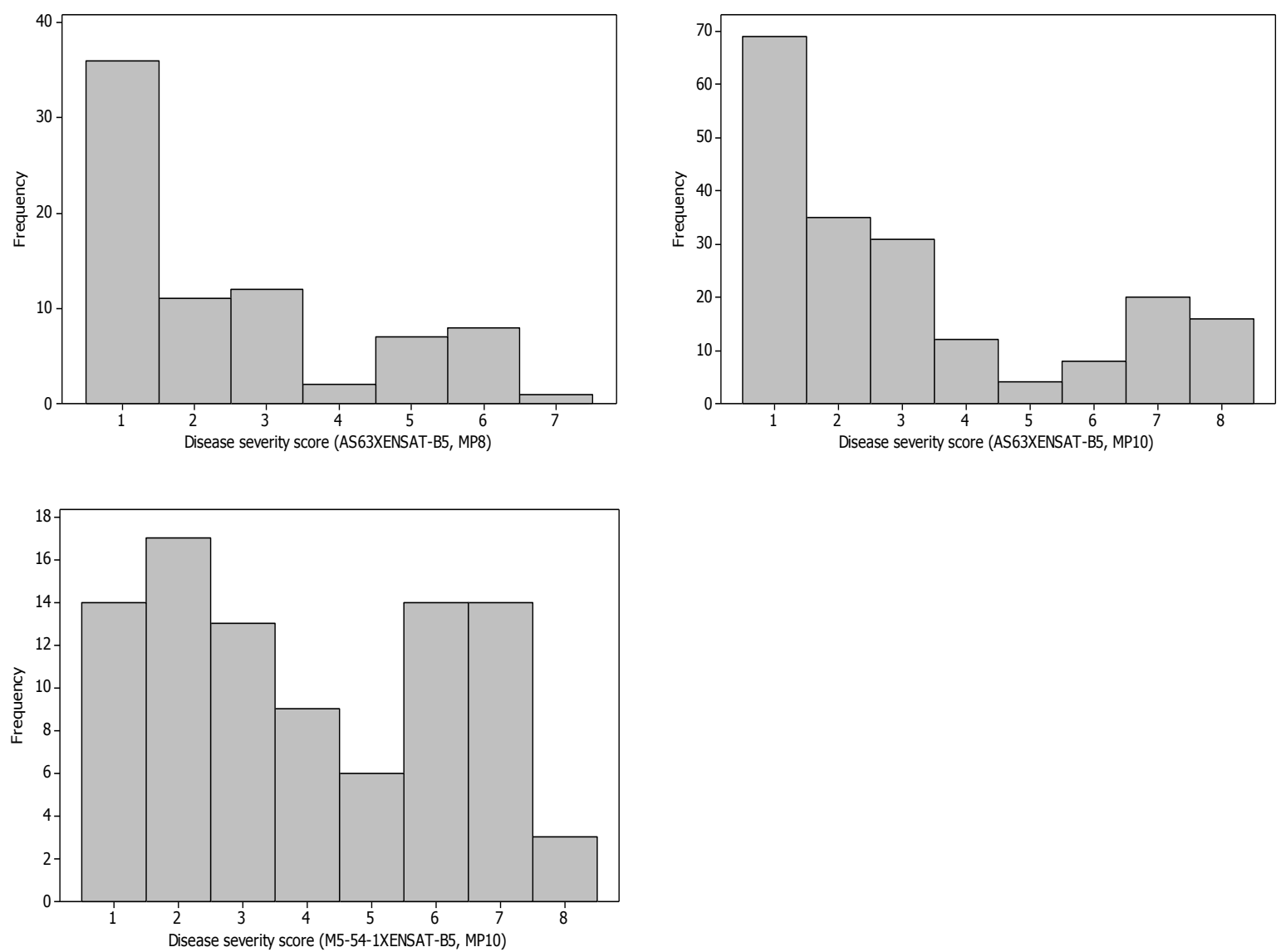

شكل 1- توزيع فراوانى واكنش جمعيتهاى F2 آفتابكردان در مقابل جدايه هاى قارج عامل بيمارى ساقه سياه. درصد نكروز

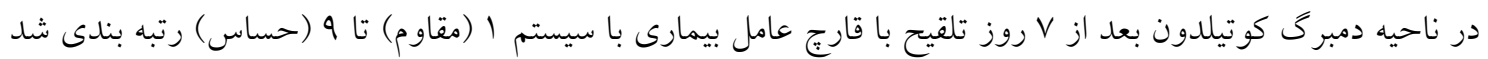
(Roustaee et al. 2000b)

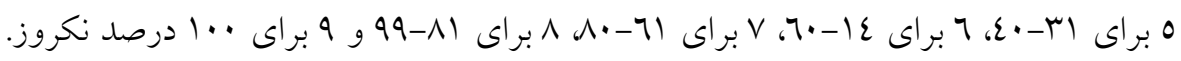

Figure 1. Frequency distribution of $\mathrm{F}_{2}$ population for resistance to black stem disease isolates. Percentage of cotyledon petiole area showing Phoma black stem were scored from 1 (resistant) to 9 (susceptible) as proposed by Roustaee et al. (2000b), seven days after inoculation, where 1, 0-5\% petiole area with necrosis spreading downward into the stem; $2,6-10 \% ; 3,11-20 \% ; 4,21-30 \%$; $5,31-40 \% ; 6,41-60 \% ; 7,61-80 \% ; 8,81-99 \%$; and $9,100 \%$

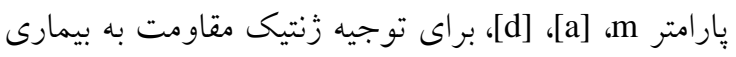
ساقه سياه مناسب نبوده و مدلهاى كاملترى كه اثرات

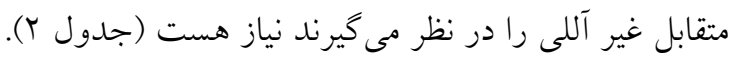

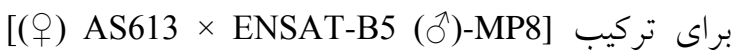
بهترين مدل براى توجيه توارث مقاومت مدل با اجزاى مجموع اثرات افزايشى [a]، اثرات غالبيت [d] و مجموع اثر متقابل بين اثرات غالبيت × غالبيت [dd] مىباشد. مقدار بالاى اثر غالبيت [d] در مقايسه با اثر افزايشى [a] حاكى
نسل اول حاصل از تلاقى والدين واريانس تنها ناشى از

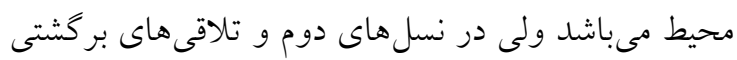

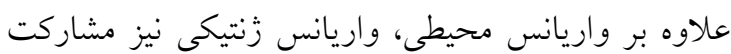
دارد كه ممكن است باعث ناهمخنى واريانس نسل ها شود.

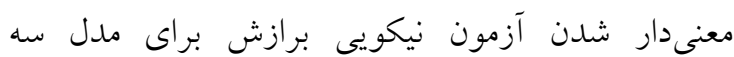

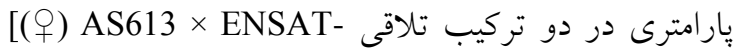

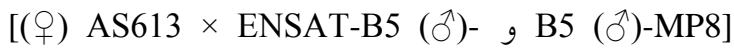
نشان مىدهد كه مدل افزايشى- غالبيت با با MP10] 


$$
\text { جدول ا- مقايسه ميانخين نسلها به همراه برآورد اثرات در مدلهاى افزايشى غالبيت و إيستازى دو گانه. }
$$

Table 1. Generation mean comparison along with estimates of genetic effects in additive-dominance and duplicate epistasis models

\begin{tabular}{|c|c|c|c|c|c|c|}
\hline \multirow{3}{*}{ Item } & \multicolumn{4}{|c|}{ () AS613 (P2) × ENSAT-B5 (P1) (び) } & \multirow{2}{*}{\multicolumn{2}{|c|}{$\begin{array}{c}\text { (中) M5-54-1 (P2) } \times \text { ENSAT-B5 } \\
(\mathrm{P} 1)\left(\mathrm{d}^{\text {( })}\right. \\
\text { MP10 isolate }\end{array}$}} \\
\hline & \multicolumn{2}{|c|}{ MP8 isolate } & \multicolumn{2}{|c|}{ MP10 isolate } & & \\
\hline & Estimate & $\mathrm{Se}$ & Estimate & $\mathrm{Se}$ & Estimate & $\mathrm{Se}$ \\
\hline \multicolumn{7}{|c|}{ Mean of Generation } \\
\hline $\mathrm{BC} 1$ & $5.4517^{\mathrm{a}}$ & 0.4753 & $6.7215^{\mathrm{a}}$ & 0.6702 & $5.1951^{\mathrm{ab}}$ & 0.9260 \\
\hline $\mathrm{BC} 2$ & $5.4519^{\mathrm{a}}$ & 0.5242 & $4.3860^{\mathrm{b}}$ & 0.7071 & $3.9908^{\mathrm{b}}$ & 0.9439 \\
\hline $\mathrm{F} 1$ & $2.1602^{c}$ & 0.4811 & $3.1332^{\mathrm{b}}$ & 0.6148 & $4.4502^{\mathrm{ab}}$ & 0.8004 \\
\hline $\mathrm{F} 2$ & $2.4770^{\mathrm{bc}}$ & 0.4790 & $2.8456^{\mathrm{b}}$ & 0.4310 & $4.0272^{b}$ & 0.7720 \\
\hline P1 & $6.1213^{\mathrm{a}}$ & 0.4568 & $7.7398^{a}$ & 0.5890 & $6.8468^{\mathrm{a}}$ & 0.7910 \\
\hline $\mathrm{P} 2$ & $3.7278^{\mathrm{b}}$ & 0.4895 & $4.0478^{\mathrm{b}}$ & 0.6249 & $6.2235^{\mathrm{ab}}$ & 0.7828 \\
\hline \multicolumn{7}{|c|}{ Effects in Additive-dominance model } \\
\hline$[\mathrm{m}]$ & 4.9245 & 0.3348 & 5.8938 & 0.4420 & 6.5351 & 0.5564 \\
\hline$[\mathrm{a}]$ & 1.1968 & 0.3348 & 1.8460 & 0.4420 & 0.3116 & 0.5564 \\
\hline$[\mathrm{d}]$ & -4.8949 & 1.1687 & -6.0964 & 1.2576 & -5.0159 & 1.9033 \\
\hline \multicolumn{7}{|c|}{ Effects in Epistatic digenic model } \\
\hline$[\mathrm{m}]$ & -6.9661 & 2.3795 & -4.7613 & 2.7234 & 4.2220 & 4.1754 \\
\hline$[\mathrm{a}]$ & 1.1376 & 0.3317 & 1.8430 & 0.4420 & 0.3095 & 0.5671 \\
\hline [d] & 28.5811 & 5.7597 & 22.6747 & 7.1518 & -0.9242 & 10.4032 \\
\hline [aa] & 11.8847 & 2.3563 & 10.6516 & 2.6873 & 2.2727 & 4.1367 \\
\hline [ad] & -2.2968 & 1.5460 & 0.9733 & 2.1916 & 1.7813 & 2.9209 \\
\hline [dd] & -19.3708 & 3.5704 & -14.7307 & 4.6531 & 1.0657 & 6.5385 \\
\hline
\end{tabular}

درصد نكروز در ناحيه دمبرى كوتيلدون بعد از V روز تلقيح با قارج عامل بيمارى با سيستم ا (مقاوم) تا 9 (حساس) رتبه بندى شد ( Roustaee et

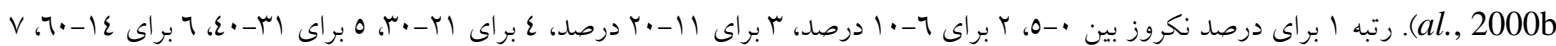

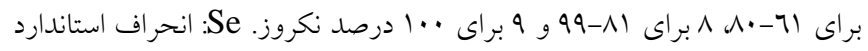

Percentage of cotyledon petiole area showing Phoma black stem were scored from 1 (resistant) to 9 (susceptible) as proposed by Roustaee et al. (2000b), seven days after inoculation, where 1, 0-5\% petiole area with necrosis spreading downward into the stem; $2,6-10 \% ; 3,11-20 \% ; 4,21-30 \% ; 5,31-40 \% ; 6,41-60 \% ; 7,61-80 \% ; 8$,

$81-99 \%$; and 9, 100\%. Se: standard error

مضاعف است (Nakhjavan et al., 2012). إييستازى مضاعف به دو صورت مغلوب مضاعف و غالب مضاعف بروز مى كند. زمانى كه زن اول بصورت مغلوب از بروز زن دوم جلو گيرى نمايد و زن دوم بصورت مغلوب از اظهار زن اول جلو گيرى نمايد، إيستازى از نوع مغلوب مضاعف است. زمانى كه حضور حداقل يك زن به صورت غالب اثر زن ديخر را بيوشاند إيستازى از نوع غالب مضاعف مى باشد. اييستازى دو گانه يا مضاعف با كاهش تنوع در نسل F2 و ديخر نسلهاى در حال تفرق،

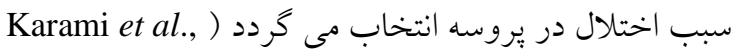

د(ㅇ) AS613 × ENSAT-B5 (ठ̋)- در تركيب تلاقى [ [مP10 مدل با اجزاء مجموع اثرات افزايشى [a]، مجموع اثرات غالبيت [d]، مجموع اثرات متقابل بين اثرات
از نقش مهم مؤلفه غالبيت در كتترل صفت در اين تركيب است. علامت مثبت اثر غالبيت [d] در مدل برازش يافته (مدل إيستاتيك) نشان مىدهد كه غالبيت در برخى مكان هاى زنى در جهت مثبت يعنى افزايش صفت/ نمره Babaei et al., ( بيمارى (كاهش مقاومت) عمل مى كند 2012). معنى دار بودن اثر متقابل غالبيت × غالبيت [dd] دلالت بر وجود اثرات اييستازى در توارث اين صفت دارد. اين امر با توجه به بلى زنيك بودن صفت قابل توجيه است. ميزان اثر متقابل غير آللى غالبيت × غالبيت [dd] نيز بزركتر از اثر افزايشى [a] ولى منفى است. علامت منفى اثرات متقابل غالبيت × غالبيت [dd] حاكى از مشاركت اين اثرات در جهت كاهش صفت/ نمره بيمارى (افزايش مقاومت) مىباشد (Mohammadi et al., 2012). علامت مخالف [d] و [dd] نشاندهنده إيستازى دو كانه يا 
افزايشى در كنترل مقاومت است. بنابراين زنتيك مقاومت در مقابل r جدايه قارج عامل بيمارى متفاوت است و لازم است در طراحى بروزههاى اصلاح براى مقاومت در نظر كرفته شود. نتايج فوق در تطابق با نتايج مطالعات قبلى (Darvishzadeh et al., 2007) مبنى بر مقاومت جدايه اختصاصى در اين وياتوسيستم مىباشد. محمدى و همكاران (Mohammadi et al., 2012) در بررسى توارث مقاومت به بيمارى ستيتوريوز بركى در گندم در شرايط كترل شده با روش تجزيه ميانخين نسل ها نشان دادند كه اثرات افزايشى، غالبيت و إيستازى در كتترل مقاومت نقش دارد و بر اساس نتايج ايشان نقش اثرات غالبيت و اثرات متقابل غالبيت × غالبيت در كنترل صفت بيشتر از اثرات افزايشى بود. بنابراين آنها روشهاى مبتنى بر هيبريداسيون و يا روش گزينش در نسلهاى بيشرفته و

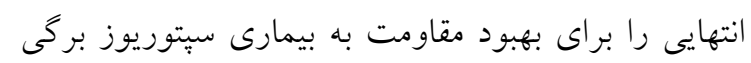
كندم بيشهاد كردند. در بررسى نحوه توارث مقاومت به بيمارى سفيدى يودرى جو در مرحله گياه بالغ توسط نقوى و همكاران (Naghavi et al., 2001) نشان داده شد كه علاوه بر اثرات افزايشى و غالبيت، اثرات اييستازى نيز نقش مهمى در كنترل مقاومت دارند. ولى واريانس غالبيت نسبت به واريانس افزايشى نقش مهمترى را در كنترل
افزايشى × افزايشى [aa] و مجموع اثر متقابل بين اثرات غالبيت × غالبيت [dd] بهترين مدل براى توجيه توارث صفت مقاومت مىباشد (جدول Y). معنىدار بودن اثرات متقابل افزايشى × افزايشى [aa] و غالبيت × غالبيت [dd] بر وجود اثرات اييستازى در توارث اين صفت دلالت

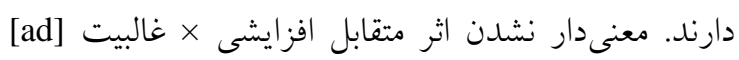
ممكن است به علت خنتى كردن آثار مثبت و منفى در مكانهاى زنى متفاوت باشد (Mostafavi et al., 2005). اين نوع اثر اييستازى نمىتواند به وسيله انتخاب (خصوراً در نسلهاى اوليه در حال تفرق) تثبيت شود. حضور اثر افزايشى [a] و اثر متقابل افزايشى × افزايشى [aa] بر اهميت بيشتر اثرات زنتيكى افزايشى در اين تركيب تلاقى در كنترل صفت مقاومت دلالت دارد. براى اين تركيب نيز علامت اثر غالبيت [d] در مدل برازش يافته ابيستاتيك مثبت است كه نشاندهنده تمايل نتاج به سمت والد حساس مىباشد (Rabiei and Ghorbanipour, 2011). علامت منفى غالبيت × غالبيت [dd] نيز حاكى از مشاركت بالاى اين اثر در مقاومت مىباشد (جدول ()). مقايسه مدل هاى توجيه كننده مقاومت در دو تركيب تلاقى نشان مى [(ㅇ) AS613 × ENSAT-B5 (ठ̋)- دهد كه براى تركيب

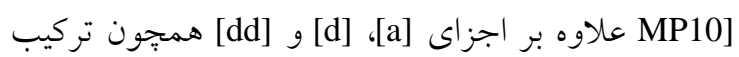
× ENSAT-B5 (ठ̋)-MP8] در مدل وارد شده است كه نشان دهنده تأثير بيشتر اثرات جدول r- آزمون F و الد تيب براى كفايت مدل افزايشى غالبيت

Table 2. Wald-type F-test for adequacy of additive-dominance model

\begin{tabular}{|c|c|c|c|c|c|c|c|c|c|}
\hline \multirow{3}{*}{ Source } & \multicolumn{6}{|c|}{ (ㅇ) AS613 × ENSAT-B5 (ठ } & \multirow{2}{*}{\multicolumn{3}{|c|}{$\frac{(\text { () }) \text { M5-54-1 × ENSAT-B5 (ठ) }}{\text { MP10 isolate }}$}} \\
\hline & \multicolumn{3}{|l|}{ MP8 isolate } & \multicolumn{3}{|l|}{ MP10 isolate } & & & \\
\hline & $\begin{array}{l}\text { Denominator } \\
\text { df }\end{array}$ & $\begin{array}{l}\text { Wald- } \\
\text { F }\end{array}$ & $\begin{array}{c}\mathrm{P}- \\
\text { value }\end{array}$ & $\begin{array}{l}\text { Denominator } \\
\text { df }\end{array}$ & $\begin{array}{l}\text { Wald- } \\
\text { F }\end{array}$ & $\begin{array}{c}\mathrm{P}- \\
\text { value }\end{array}$ & $\begin{array}{l}\text { Denominator } \\
\text { df }\end{array}$ & $\begin{array}{l}\text { Wald- } \\
\text { F }\end{array}$ & $\begin{array}{c}\mathrm{P}- \\
\text { value }\end{array}$ \\
\hline \multicolumn{10}{|c|}{ Additive-dominance model } \\
\hline [a] & 6.76 & 6.59 & 0.0383 & 12.5 & 26.20 & 0.0002 & 8.62 & 0.60 & 0.4577 \\
\hline [d] & 9.02 & 15.60 & 0.0033 & 14.4 & 14.95 & 0.0016 & 9.27 & 7.68 & 0.0211 \\
\hline Lack fit & 5.80 & 10.21 & 0.0098 & 11.9 & 6.20 & 0.0087 & 8.46 & 1.11 & 0.3966 \\
\hline \multicolumn{10}{|c|}{ Epistatic digenic model } \\
\hline [a] & 6.61 & 6.08 & 0.0451 & 13.3 & 24.56 & 0.0002 & 9.02 & 0.58 & 0.4645 \\
\hline [d] & 9.22 & 14.89 & 0.0037 & 15.5 & 13.64 & 0.0021 & 9.66 & 7.54 & 0.0213 \\
\hline [aa] & 5.78 & 1.24 & 0.3096 & 13.1 & 10.79 & 0.0059 & 9.16 & 2.50 & 0.1478 \\
\hline [ad] & 5.69 & 1.34 & 0.2935 & 12.4 & 0.40 & 0.5386 & 8.60 & 0.36 & 0.5650 \\
\hline [dd] & 5.30 & 29.43 & 0.0024 & 12.4 & 10.02 & 0.0074 & 8.67 & 0.03 & 0.8743 \\
\hline
\end{tabular}


حاصل از اين تركيبها توليد هيبريد بسيار موفقيتآميز

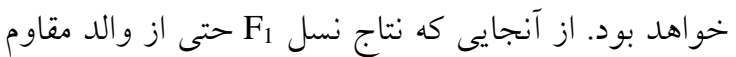

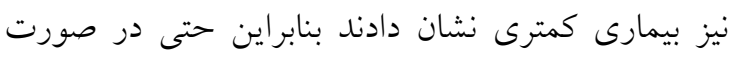
تلاقى دو لاين مقاوم و حساس نيز مىتوان هيبريدهايى نئي

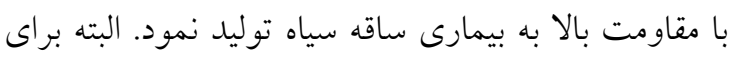

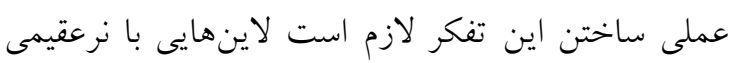
زرنتيكى -سيتويلاسمى توليد و توسعه يابند ( Karami et .(al., 2011 اطلاعات در مورد نحوه عمل زنها، استراتزى اصلاحى براى يك صفت را تعيين مى كند. در حالت كلى برآورد بالاى اثر غالبيت و اييستازى، توجه به توليد بذر هيبريد و

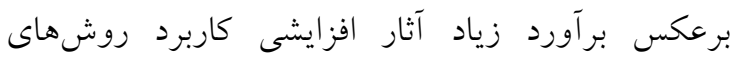

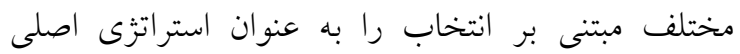
اصلاح يك صفت تداعى مى كند. براساس نتايج تحقيق

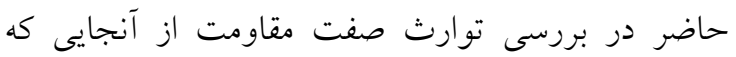

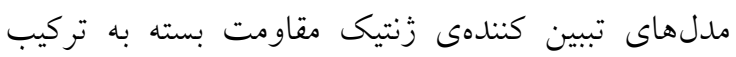
تلاقى متفاوت هستند، مىتوان نتيجه كرفت كه مكانيسم دركير در مقاومت در زنوتيبهاى فوق فرق مى كند. بنابراين استراتزىهاى اصلاحى متفاوتى براى گزينش و اصلاح واريتههاى با مقاومت بيشتر از جمعيتهاى در

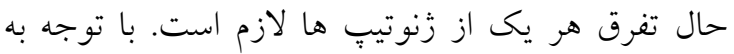

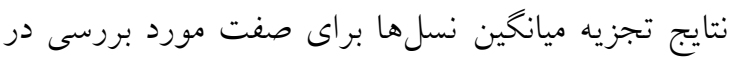

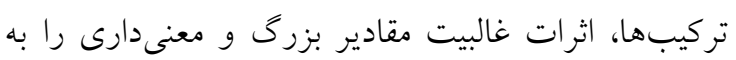
خود اختصاص دادند، در حالى كه اثرهاى افزايشى با لناليا

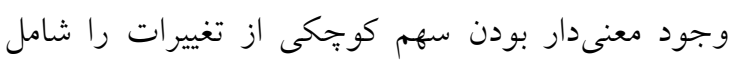

شلنه.
در ارزيابى زنتيك مقاومت به سفيدى بودرى در جو نشان داده شد كه مقاومت به وسيله اجزاى افزايشى، غالبيت و

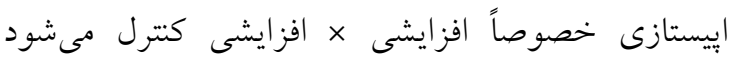

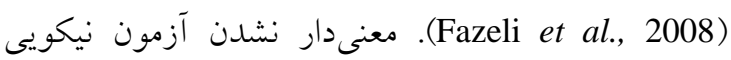

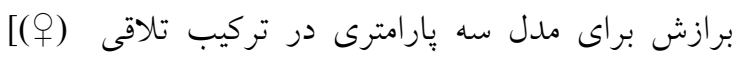

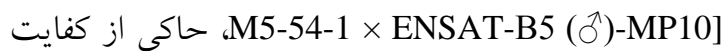
مدل افزايشى- غالبيت براى توجيه زنتيك مقاومت به بيمارى ساقه سياه بود (جدول r). در اين تركيب نيز مقدار بالا و معنىدار اثر غالبيت [d] در مقايسه با اثر افزايشى [a] حاكى از نقش مهم مؤلفه غالبيت در كتترل صفت در اين تركيب است. براى اين تركيب تلاقى، علامت منفى اثر غالبيت [d] نشان مىدهد كه جهت

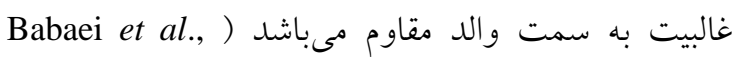

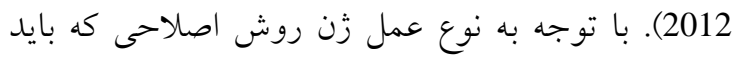

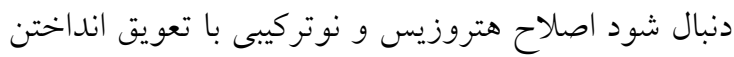
انتخاب به نسلهاى بعدى مىباشد. در بررسى زنتيكى

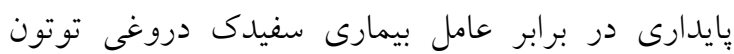

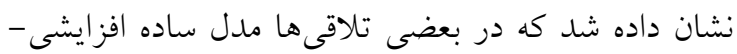
غالبيت براى توجيه مقاومت مناسب مىباشد در حالى كه

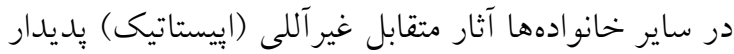
كَثته به طورى كه مدل شش پارامترى متر و جينكز

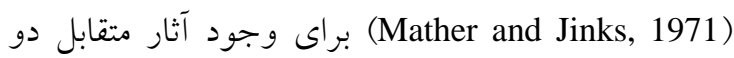

زنى برازش داده شدند (Honarnejad et al., 2001).

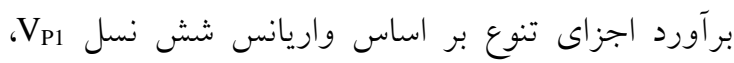

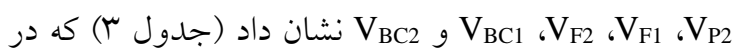
تلاقى هاى مورد بررسى سهم واريانس غالبيت قابل توجه

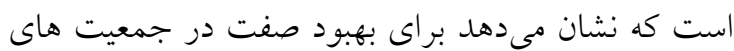

جدول r- برآورد اجزاى واريانس با حداكثر درست نمايى محدود شده در مدل خطى مخلوط

Table 3. Estimation of variance components using REML (restricted maximum likelihood) in mixed linear model

\begin{tabular}{|c|c|c|c|c|c|c|}
\hline \multirow{3}{*}{ Variance } & \multicolumn{4}{|c|}{ (क) AS613 × ENSAT-B5 (ô) } & \multirow{2}{*}{\multicolumn{2}{|c|}{$\begin{array}{l}\text { (o) M5-54-1 } \times \text { ENSAT-B5 (0) } \\
\text { MP10 isolate }\end{array}$}} \\
\hline & & late & & & & \\
\hline & Estimate & $\mathrm{Se}$ & Estimate & $\mathrm{Se}$ & Estimate & $\mathrm{Se}$ \\
\hline$\delta_{A}^{2}$ & 0.0084 & 2.5007 & 0.0000 & 1.8222 & 1.9728 & 3.0204 \\
\hline$\delta_{D}^{2}$ & 2.5925 & 2.0215 & 1.7200 & 1.6949 & 2.5597 & 1.0486 \\
\hline$\delta_{A D}$ & 1.8719 & 0.9171 & 2.1503 & 0.8251 & 0.7473 & 0.7992 \\
\hline$\delta_{P}^{2}$ & 0.3736 & 0.3007 & 0.8473 & 0.3988 & 1.6212 & 0.8675 \\
\hline$\delta_{e}^{2}$ & 5.3624 & 1.1658 & 5.1658 & 1.0683 & 4.7905 & 0.9104 \\
\hline
\end{tabular}


مطالعه در تركيبها، توليد ارقام هيبريد براى افزايش

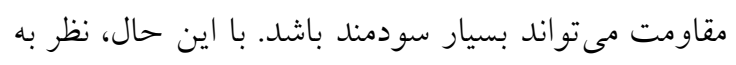

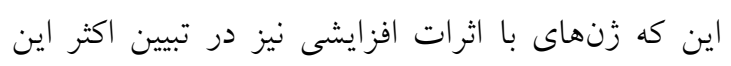

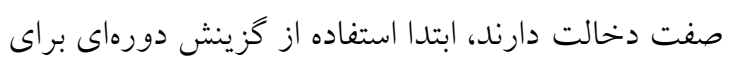

تجميع اين زنها و گزينش لاين هاى مقاوم سودمند خو اهد

بود.

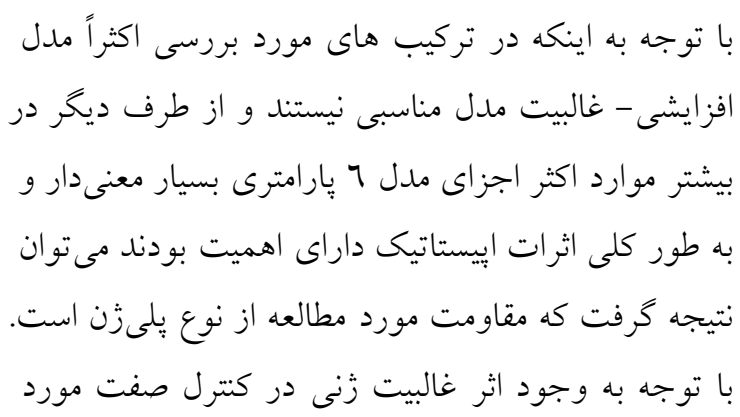

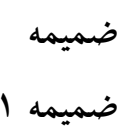

برنامه SAS براى تجزيه ميانخين نسل ها با استفاده از مدل خطى مخلوط

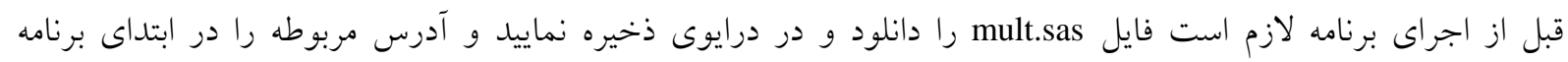

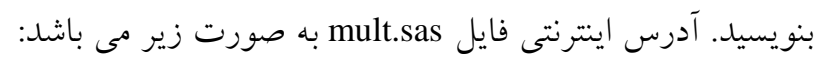

https://www.uni-hohenheim.de/bioinformatik/beratung/toolsmacros/sasmacros/mult.sas

$\%$ INCLUDE 'c:Imult.sas';

data a;

input

rep plot plant gen $\$$ dss;

lackfit=gen;

$\mathrm{VA}=\mathbf{0} ; \mathrm{VD}=\mathbf{0}$;

if gen="P1" then do;

$\mathrm{a}=\mathbf{1} ; \mathrm{d}=\mathbf{0}$; group $\mathbf{1}$; end;

if gen="P2" then do;

$\mathrm{a}=\mathbf{- 1} ; \mathrm{d}=\mathbf{0}$; group $=\mathbf{1}$; end;

if gen="F1" then do;

$\mathrm{a}=\mathbf{0} ; \mathrm{d}=\mathbf{1} ;$ group $\mathbf{= 1}$; end;

if gen="F2" then do;

$\mathrm{VA}=\mathbf{1} ; \mathrm{VD}=\mathbf{1} ; \mathrm{a}=\mathbf{0} ; \mathrm{d}=\mathbf{0 . 5}$; group=2; end;

if gen="B1" then do;

$\mathrm{VA}=\mathbf{0 . 5} ; \mathrm{VD}=\mathbf{1} ; \mathrm{a}=\mathbf{0 . 5} ; \mathrm{d}=\mathbf{0 . 5}$; group $=3$; end;

if gen="B2" then do;

$\mathrm{VA}=\mathbf{0 . 5} ; \mathrm{VD}=\mathbf{1} ; \mathrm{a}=-\mathbf{0 . 5} ; \mathrm{d}=\mathbf{0 . 5}$; group $=\mathbf{4}$; end;

plant $=\_N_{-}$;

datalines;

$\begin{array}{lllll}1 & 1 & 1 & \text { P1 } & 8 \\ 1 & 1 & 2 & \text { P1 } & 8 \\ 1 & 1 & 3 & \text { P1 } & 1 \\ . & . & . & . & . \\ . & . & . & . & . \\ . & . & . & . & . \\ 3 & 15 & 14 & \text { F1 } & 1 \\ 3 & 15 & 15 & \text { F1 } & 3\end{array}$

data $\operatorname{lin} 3$;

input parm row col1-col6; 


\begin{tabular}{llllllll}
\multicolumn{2}{l}{ datalines; } & & & \\
1 & 1 & 0.5 & 0 & 0 & 0 & 0 & 0 \\
1 & 2 & 0 & 0.5 & 0 & 0 & 0 & 0 \\
1 & 3 & 0 & 0 & 0 & 0 & 0 & 0 \\
1 & 4 & 0 & 0 & 0 & 1 & 0 & 0 \\
1 & 5 & 0 & 0 & 0 & 0 & 0 & 0 \\
1 & 6 & 0 & 0 & 0 & 0 & 0 & 0 \\
2 & 1 & 1 & 0 & 0 & 0 & 0 & 0 \\
2 & 2 & 0 & 1 & 0 & 0 & 0 & 0 \\
2 & 3 & 0 & 0 & 0 & 0 & 0 & 0 \\
2 & 4 & 0 & 0 & 0 & 1 & 0 & 0 \\
2 & 5 & 0 & 0 & 0 & 0 & 0 & 0 \\
2 & 6 & 0 & 0 & 0 & 0 & 0 & 0 \\
3 & 1 & -1 & 0 & 0 & 0 & 0 & 0 \\
3 & 2 & 0 & 1 & 0 & 0 & 0 & 0 \\
3 & 3 & 0 & 0 & 0 & 0 & 0 & 0 \\
3 & 4 & 0 & 0 & 0 & 0 & 0 & 0 \\
3 & 5 & 0 & 0 & 0 & 0 & 0 & 0 \\
3 & 6 & 0 & 0 & 0 & 0 & 0 & 0
\end{tabular}

/*lack of fit for additive-dominance model*/

proc mixed data $=$ a covtest;

class gen rep plant plot lackfit;

model dss $=$ a d lackfit

/htype $=\mathbf{1}$ ddfm=kr solution;

random gen/subject=plant*plot type=lin(3) ldata=lin3;

random int/sub=plot;

run;

$/ *$ estimate $[\mathrm{a}]$ and $[\mathrm{d}] * /$

proc mixed data $=a$ covtest;

class group gen rep plant plot;

model dss $=$ a d a*a a*d d*d

/htype $=\mathbf{1}$ ddfm $=\mathrm{kr}$ solution;

random int $/ \mathrm{sub}=$ plot;

run;

/*mean comparison*/

ods output lsmeans=lsmeans diffs $=$ diffs;

proc mixed data $=\mathrm{a}$;

class gen rep plant plot;

model dss $=$ gen $/$ htype $=\mathbf{1} \mathrm{ddfm}=\mathrm{kr}$ solution;

random int $/ \mathrm{sub}=$ plot;

random gen/subject=plant*plot type=lin(3) ldata=lin3;

lsmeans gen/pdiff;

$\%$ mult $($ trt $=$ gen $)$;

run;

براى آزمون همخنى واريانس بين گروهها، بعد از گزاره random در هر تجزيه از گزاره زير استفاده مىشود. براساس نتايج اخر مقدار عددى AIC وقتى گزاره repeated در مدل كذاشته شود كمتر از حالتى باشد كه گزاره repeated از مدل حذف شود مىتوان نتيجه گرفت مدل در حالى كه گروهبندى در تجزيه لحاظ شود برازش بهترى را نشان مىدهل. بدين مفهوم كه نسلها واريانس متفاوتى داشته و همخن نيستند.

repeated /group=group; 


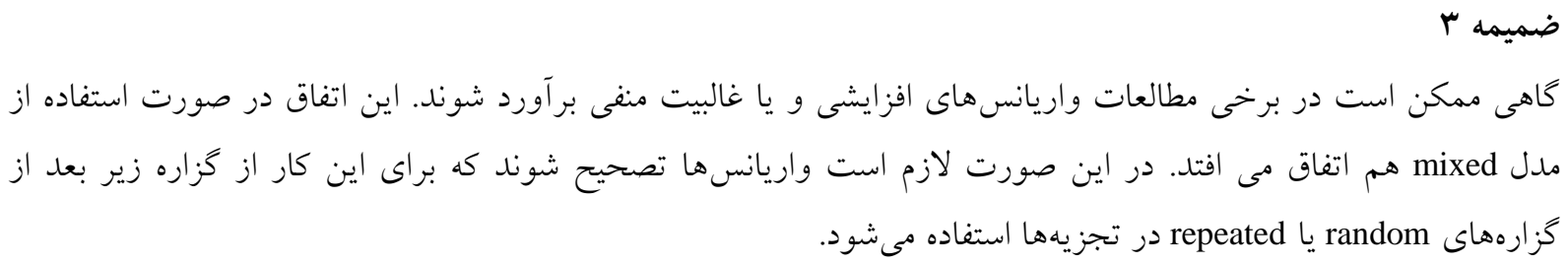

\section{References}

Babaei, H.R., Khanghah, H.Z. and Taleei, A. (2012). Genetic analysis of agronomic traits and seed shattering resistance in soybean (Glycine max L.). Seed and Plant Improvement Journal, 28(4): 593-609 (In Persian).

Butron, A., Malvar, R.A., Revilla, P., Soengas, P., Ordás, A. and Geiger, H.H. (2002). Rind puncture resistance in maize: inheritance and relationship with resistance to pink stem borer attack. Plant Breeding, 121(5): 378-382.

Butruille, D.V., Silva, H.D., Kaeppler, S.M. and Coors, J.G. (2004). Response to selection and genetic drift in three populations derived from the Golden Glow maize population. Crop Science, 44(5): 1527-1534.

Carson, M.L. (1991). Relationship between Phoma black stem severity and yield losses in hybrid sunflower. Plant Disease, 75(11): 1150-1153.

Checa, O., Ceballos, H. and Blair, M.W. (2006). Generation means analysis of climbing ability in common bean (Phaseolus vulgaris L.). Journal of Heredity, 97(5): 456-465.

Darvishzadeh, R., Poormohammad Kiani, S., Huguet, T. and Sarrafi, A. (2008a). Genetic variation and identification of molecular marker associated with partial resistance to Phoma macdonaldii in gamma-irradiation-induced mutants of sunflower. Canadian Journal of Plant Pathology, 30: 106-114.

Darvishzadeh, R., Hewezi, T., Gentzbittel, L. and Sarrafi, A. (2008b). Differential expression of defence-related genes between compatible and partially compatible sunflower-Phoma macdonaldii interactions. Crop Protection, 27(3): 740-746.

Darvishzadeh, R., Dechamp-Guillaume, G., Hewezi, T. and Sarrafi, A. (2007). Genotype-isolate interaction for resistance to black stem in sunflower (Helianthus annuus L.). Plant Pathology, 56(4): 654-660.

Debaeke, P. and Pérès, A. (2003). Influence of sunflower (Helianthus annuus L.) crop management on Phoma black stem (Phoma macdonaldii Boerema). Crop Protection, 22(5): 741-752.

Dorri, P., Khavari Khorasani, S., Vali Zadeh, M. and Taheri, P. (2015). Investigation the heritability and gene effects on yield and some agronomic traits of maize (Zea mays L.). Plant Genetic Researches, 1(2): 33-42 (In Persian).

Fazeli, A., Babaeian Jelodar N., Naghavi, M.R. and Nikkhah H.R. (2008). Genetic evaluation of powdery mildew progress in two different barley crosses. Applied Entomology and Phytopathology, 76(1): 15-25 (In Persian).

Ghannadha, M.R. (2000). Gene function for resistance to yellow rust in wheat. Iranian Journal of Crop Sciences, 3: 397-407 (In Persian). 
Gulya, T., Rashid, K.Y. and Masirevic, S.M. (1997). Sunflower disease: Phoma black stem. In: Schneiter AA, ed. Sunflower Technology and Production. Madison, WI, USA: ASA, CSSA, SSSA: Agronomy Monograph no, 35: 319-22.

Hinze, L.L. and Lamkey, K.R. (2003). Absence of epistasis for grain yield in elite maize hybrids. Crop Science, 43(1): 46-56.

Honarnejad, R., Shoai Deylami, M. and Mesbah, M. (2001). Genetics of resistance to blue mould (Peronospora tabacina Adam) of tobacco. Journal of Science and Technology of Agriculture and Natural Resources, 5(2): 65-74 (In Persian).

Hu, J., Seiler, G. and Kole, C. (2010). Genetics, Genomics and Breeding of Sunflower. CRC Press, Boca Raton, Florida, USA.

Jovanovic, D. and Marinkovic, R. (2006). Use of additive-dominant model in genetic analysis of some quantitative characteristics in sunflower. In XIII EUCARPIA Biometrics in Plant Breeding Section Meeting 30 August - 1 September 2006, Agriculturae Conspectus Scientificus, 71(1): pp 54, Zagreb, Croatia.

Karami, E., Sabagh Pur, S.H., Naghavi, M.R. and Taeeb, M. (2011). Genetic analysis of earliness in chickpea (Cicer arietinum L.) using generation mean analysis. Iranian Journal of Pulses Research, 2(2): 63-68 (In Persian).

Kashiwagi, J., Krishnamurthy, L., Gaur, P.M., Chandra, S. and Upadhyaya, H.D. (2008). Estimation of gene effects of the drought avoidance root characteristics in chickpea (Cicer arietinum L.). Field Crops Research, 105(1): 64-69.

Kearsey, M.J. and Pooni, H.S. (1996). The Genetical Analysis of Quantitative Traits. Chapman and Hall, London, UK.

Kusterer, B., Muminovic, J., Utz, H.F., Piepho, H.P., Barth, S., Heckenberger, M., Meyer, R.C., Altmann, T. and Melchinger, A.E. (2007). Analysis of a triple testcross design with recombinant inbred lines reveals a significant role of epistasis in heterosis for biomass-related traits in Arabidopsis. Genetics, 175(4): 2009-2017.

Lamkey, K.R. and Lee, M. (1993). Quantitative genetics, molecular markers, and plant improvement In: B. C. Imrie and J. B. Hacker (eds.) Focused plant improvement: Towards responsible and sustainable agriculture. Proc. 10th Australian Plant Breeding Conf., Gold Coast, 18-23 April 1993, pp 104-115, Canberra, AU.

Lynch, M. and Walsh, B. (1998). Genetics and Analysis of Quantitative Traits. Sinauer, Sunderland, Massachusetts, USA.

Malvar, R.A., Revilla, P., Moreno-González, J., Butrón, A., Sotelo, J. and Ordás, A. (2008). White maize: genetics of quality and agronomic performance. Crop Science, 48(4): 1373-1381.

Mather, K., and Jinks, J.L. (1971). Biometrical Genetics, 2nd ed., Chapman and Hall, London, UK.

Mihaljevic, R., Utz, H.F. and Melchinger, A.E. (2005). No evidence for epistasis in hybrid and per se performance of elite European flint maize inbreds from generation means and QTL analyses. Crop Science, 45(6): 2605-2613.

Mohammadi, M., Ramzanpour, S.S., Navabpour, S., Soltanloo, H., Kalate Arabi, M. and Kia, Sh. (2012). Study on inheritance of resistance to Septoria tritici Blotch of wheat by generation mean analysis. Journal of Plant Production, 19(4): 1-18 (In Persian).

Molaei, B., Moghaddam, M., Alavikia S.S. and Bandeh Hagh A. (2016). Generation mean analysis for several agronomic and physiologic traits in bread wheat under normal and water deficit stress conditions. Plant Genetic Researches, 3(2): 1-10 (In Persian).

Mostafavi, K.H., Hosseinzadeh, A.H. and Khaneghah, H.Z. (2005). Genetic analysis of yield and correlated traits in bread wheat (Triticum aestivum). Iranian Journal of Agriculture Science, 36(1): 187-197.

Naghavi, M.R., Ghannadha, M.R. Yazdi Samadi, B. and Torabi, M. (2001). Inheritance of resistance to barley powdery mildew at adult plant stage. Seed and Plant Improvement Journal, 18(2): 140-150 (In Persian).

Nakhjavan, S., Bihamta, M.R., Darvish, F., Sorkhi, B. and Zahravi, M. (2012). Heritability of agronomic traits in the progenies of a cross between two drought tolerant and susceptible barley genotypes in terminal drought stress conditions. Iranian Journal of Crop Sciences, 14(2):136-154 (In Persian).

Piepho, H.P. (1997). Analysis of a randomized complete block design with unequal subclass numbers. 
Agronomy Journal, 89: 718-723.

Piepho, H.P. and Möhring, J. (2010). Generation means analysis using mixed models. Crop Science, 50(5): 1674-1680.

Rabiei, B. and Ghorbanipour, A. (2011). Assessment of gene action and heritability of important agronomic traits in rice (Oryza sativa L.) using generation mean analysis. Iranian Journal of Crop Sciences, 13(2): 408-423 (In Persian).

Rauf, S. (2008). Breeding sunflower (Helianthus annuus L.) for drought tolerance. Communications in Biometry and Crop Science, 3: 29-44.

Roustaee, A., Costes, S., Dechamp-Guillaume, G. and Barrault, G. (2000a). Phenotypic variability of Leptosphaeria lindquistii (Phoma macdonaldii), a fungal pathogen of sunflower. Plant Pathology, 49(2): 227-234.

Roustaee, A., Barrault, G., Dechamp-Guillaume, G., Lesigne, P. and Sarrafi, A. (2000b). Inheritance of partial resistance to black stem (Phoma macdonaldii) in sunflower. Plant Pathology, 49(3): 396-401.

Sackston, W.E. (1992). On a treadmill: breeding sunflowers for resistance to disease. Annual Review of Phytopathology, 30(1): 529-551.

Smith, C.W., Braden, C.A. and Hequet, E.F. (2009). Generation mean analysis of near-long-staple fiber length in TAM 94L-25 upland cotton. Crop Science, 49(5): 1638-1646.

Wilson, J.A., Glover, D.V. and Nyquist, W.E. (2000). Genetic effects of the soft starch (h) and background loci on volume of starch granules in five inbreds of maize. Plant Breeding, 119(2): 173-176.

Zalapa, J.E., Staub, J.E. and McCreight, J.D. (2006). Generation means analysis of plant architectural traits and fruit yield in melon. Plant Breeding, 125(5): 482-487. 


\title{
Generation Mean Analysis to Black Stem Disease Resistance in Sunflower (Helianthus annuus L.), using Mixed Linear Models
}

\section{Reza Darvishzadeh ${ }^{1, *}$, Hadi Alipour ${ }^{2}$ and Ahmad Sarrafi ${ }^{3}$}

1- Professor, Department of Plant Breeding and Biotechnology, Faculty of Agriculture, Urmia University, Urmia, Iran

2- Assistant Professor, Department of Plant Breeding and Biotechnology, Faculty of Agriculture, Urmia University, Urmia, Iran

3- Professor, Functional Ecology Laboratory (EcoLab), École Nationale Supérieure Agronomique de Toulouse, Institut National Polytechnique, Toulouse, France

(Received: April 21, 2017 - Accepted: September 5, 2017)

\begin{abstract}
Black stem disease is one of the most important fungi diseases in sunflower. Information about the mode of heritability and the effects of genes controlling trait could be most important for selecting breeding methods to black stem disease resistance. In this study, genotypes ENSAT-B5 and AS613 and a mutant genotype M5-54-1 with different response to MP8 and MP10 isolates were selected and $\mathrm{F}_{1}, \mathrm{~F}_{2}, \mathrm{BC}_{1}$ and $\mathrm{BC}_{2}$ generations were made from ENSAT-B5×AS613 and ENSAT-B5×M5-54-1 crosses. Generations of crossing and parents of each set were planted in a completely randomized design with three replications and infected by M8 and M10 isolates. With the exception of the [(O) M5-54-1 $\times$ ENSAT-B5 (ठ)-MP10] cross, the lack of fit test of simple three parametric additivedominance models for the [() AS613 $\times$ ENSAT-B5 (ð)-MP8] and [(ㅇ) AS613 $\times$ ENSAT-B5 (ð)MP10] crosses were significant, indicating the presence of non-allelic interactions in the inheritance of the black stem disease resistance. In the estimated models for the different crosses, high and significant amount of dominant effects and dominant $\times$ dominant interactions suggested the importance of non-additive genetic effects. Therefore, selection for this trait in early generation could not be effectively successful and hybrid development is highly recommended for increasing the resistance to the black stem disease.
\end{abstract}

Keywords: Biotic stress, Epistasis, Mating design, Non-additive effects, Oil crops

\footnotetext{
*Corresponding Author, E-mail: r.darvishzadeh@urmia.ac.ir
} 